\title{
A Note to Investigate the Welfare: When the Upstream Firm Enters the Downstream Market
}

\author{
Chung-Yuan Fu, Li-Chen Chou*, Shiue-Hung Lin \\ Department of Economics, National Chengchi University, Taiwan \\ Email: fuchungyuan@gmail.com, ${ }^{*}$ edcv25810@yahoo.com.tw,98258507@nccu.edu.tw
}

Received September 25, 2013; revised October 25, 2013; accepted November 3, 2013

Copyright (C) 2013 Chung-Yuan Fu et al. This is an open access article distributed under the Creative Commons Attribution License, which permits unrestricted use, distribution, and reproduction in any medium, provided the original work is properly cited.

\begin{abstract}
To investigate the changes of welfare and the degree of exploitation in consumer side when the upstream firm enters the downstream market, we construct a quantity competition model to analyze the changes in consumers' welfare and the profits of upstream and downstream firms. The main findings of this note are as follows: The markup has a negative effect in consumer's surplus and the degree of exploitation will deteriorate when the upstream firm goes into the other market. In addition, the profits in the firm which expands his production scale to downstream will decline when the markup level rises, but with no obvious effect in original downstream firm.
\end{abstract}

Keywords: Upstream; Downstream; Cournot Competition; Vertical Integration; Welfare

\section{Introduction}

In reality, some industries such like telecommunications, electric power, smart phone and so on, usually exist in a firm sells upstream output to its downstream. In some cases we can find that the upstream (downstream) firm may have more pricing or bargaining power than others under some specific circumstances. Investigating of the firms' strategies between upstream and downstream has a long history. For instance, Katz (1987) examined the welfare effect of the price discrimination in an intermediate goods market where a monopolist sells his goods to the downstream firms, and he found that the price discrimination both decreases the total output in the final good market and social welfare (see [1]). DeGraba (1990) indicated that discriminatory pricing from an upstream monopolist will decline the R\&D activities in downstream and unfavorable social welfare (see [2]). Economides (1998) considered the incentive for non-price discrimination of a monopolist in an input market who also sells goods in an oligopoly downstream market through a subsidiary (see [3]). The author found that the monopolist has the incentive to raise the costs of the rivals to its subsidiary through discriminatory quality degradation.

In the issue about the entry of an upstream monopolist into downstream markets, Sibley and Weisman (1998) pointed that the entry will not only raise the downstream

\footnotetext{
${ }^{*}$ Corresponding author.
}

rivals' costs but also bring an offsetting effect in the higher downstream price, which will reduce the demand for the input and has a negative effect in monopolist's profit (see [4]). In other words, whether to enter depends on which incentive dominates the other. Similar results also appeared in Chemla (2003), in this study the author analyzed the effect of competition among downstream firms on an upstream firm's payoff and on its incentive to integrate vertically when firms in both segments negotiate optimal contracts (see [5]). The result emphasized that the upstream firm may encourage downstream competition in response to high downstream bargaining power.

In sum, previous literature mainly indicated that discriminatory pricing tends to reduce social welfare, or the entry of an upstream monopolist into downstream markets may cause the competition degree to increase in downstream. However, no one interprets the changes of welfare or the degree of exploitation in consumer side when the upstream firm enters the downstream market. For example, Samsung is one of intermediate goods suppliers in the production process of IPhone. How does the welfare (or consumer's surplus) change when Samsung enters to the smart phone market? To fill this gap, this note constructs a simple quantity competition model to compare the changes in consumers' welfare and the profits of upstream and downstream firms. We assume that there is an upstream firm and a downstream firm origi- 
nally, both of them have monopoly power in their own market. We try to compare the difference of consumer's surplus and producer's profit with that in original circumstances when upstream firm expands his production scale and enters to downstream market.

The main findings of this note are as follows: The markup has a negative effect in consumer's surplus and the degree of exploitation will deteriorate when the upstream firm goes into the other market. In addition, the profits in the firm which expands his production scale to downstream will decline when the markup level rises, but with no obvious effect in original downstream firm.

\section{The Benchmark Model}

Imagine that there is a double monopoly framework between Country 1 and Country 2. It is assumed that there is only one producer in each country. Firm 1 in Country 1 produces a capital product, which is sold to Firm 2 in Country 2 as an intermediate input. Firm 2 produces a final product, and we assume the capital input isindispensable in the production process. The demand faced by Firm 2 is given by $p=a-b q$, where $a$ is the final good of the market size in Country $2, b$ represents the slope of the demand of the final good and $q$ is used to represent the demand quantity of final goods in the market. The marginal production cost is partly determined by the capital price which charged by Firm 1. In this section, we describe the double marginalization phenomenon between upstream and downstream production.

The Final Product Firm 2's maximization problem is:

$$
\pi_{2}^{d}=(a-b q) q-r q,
$$

where $\pi_{2}^{d}$ means the Firm 2's profit in downstream in the Country 2 and $r$ represents the unit production cost which is charged by Firm 1 . We can solve the downstream equilibrium by first order condition as following,

$$
p=\frac{a+r}{2}, q=\frac{a-r}{2 b}, \pi_{2}^{d}=\frac{(a-r)^{2}}{4 b} .
$$

The Capital Product Given the demand faced by Firm 1 is exactly $q=\frac{a-r}{2 b}$. Firm 1 's objective function is:

$$
\pi_{1}^{u}=(r-c) q .
$$

where $\pi_{1}^{u}$ displays the profit of the up-stream in the Country 1 and $c$ means the unit production cost for producing one unit capital good. Solving the Equation (3) with maximization:

$$
\begin{aligned}
& r=\frac{a-c}{2}, q=\frac{a-c}{4 b}, p=\frac{3 a+c}{4}, \\
& \pi_{2}^{d}=\frac{(a-c)^{2}}{16 b}, \pi_{1}^{u}=\frac{(a-c)^{2}}{8 b} .
\end{aligned}
$$

Because the final good is consumed in Country 2, therefore we define the global welfare ${ }^{1}$ in the benchmark is the sum of the consumer surplus of the final good and the firms' profits in upstream and downstream market:

$$
\begin{aligned}
& \text { Welfare }_{b} \\
& =\frac{(a-c)^{2}}{32}+\frac{(a-c)^{2}}{8 b}+\frac{(a-c)^{2}}{16 b}=\frac{(b+6)(a-c)^{2}}{32 b} .
\end{aligned}
$$

\section{The Extended Model}

Consider that the upstream firm wants to expand his production scale to down-stream market due to its technology advantage. Hence, the market structure of upstream in Country 1 is still the monopoly industry (the profit is the same as Equation (3)), but the final good in the industry will face the duopoly competition. In addition, in order to it exists nonnegative quantities in Firm 1, we assume that the market size is larger double times than the upstream firm's production cost plus markup level $^{2}$. Define the firms' profit functions in the downstream:

$$
\begin{gathered}
\pi_{1}^{d}=\left[a-b\left(q_{1}+q_{2}\right)\right] q_{1}-(c+m) q_{1}-f, \\
\pi_{2}^{d}=\left[a-b\left(q_{1}+q_{2}\right)\right] q_{2}-r q_{2} .
\end{gathered}
$$

where $\pi_{1}^{d}$ and $\pi_{2}^{d}$ are the profit of the downstreamsubsidiary which is constructed from the upstream monopolistic firm in Country 1 and the profit of existing firm in the downstream market; $r$ is the retail price and $f$ is other cost expenditure such like advertisement, media propaganda and so on. In addition, $q_{1}$ and $q_{2}$ respectively represent the outputsof Firm 2 and new entrant. Equations (6) and (7) indicate the downstreamsubsidiary and the Firm 2 carry on an unfair cournot-competiting game in the Country 2. In the side of the new entrant, he owns a cost-reduced advantage in production process from his patent company, i.e., his marginal cost is $c+m^{3}$, but he needs to pay a fee for the store opening. On the other hand, Firm 2 pays a higher retail price than his rival, $c+m \leq r$, however, he can save the cost of advertising or other expenditures.

Accordingly, jointly solving the first-order conditions associated with (6) and (7) yields equilibrium wholesale price, the output levels of the subsidiary and Firm 2, respectively,

\footnotetext{
${ }^{1}$ In here, global welfare is defined as the sum of total welfare of all countries. This is a general approach for calculating global welfare. Hence, we aggregate the consumer surplus in Country 2 and the producer surplus in both countries.

${ }^{2}$ In order to the retail pricing must be efficiency, the market size, $a$ is larger than the double times the $(c+m)$, otherwise the new entrant will face a high marginal cost than the existing ones.

${ }^{3}$ The parameter, $m$ not only denotes the markup power be offered by the upstream firm to its subsidiary, but also represents the "cost based transfer pricing, CBTR" in accounting issues.
} 


$$
\begin{aligned}
& p=\frac{a+r+c+m}{3}, q_{1}=\frac{a+r-2 c-2 m}{3 b}, \\
& q_{2}=\frac{a+c-2 r+m}{3 b} .
\end{aligned}
$$

The profit in upstream firm is $\pi_{1}^{u}=m q_{1}+r q_{2}-c\left(q_{1}+q_{2}\right)$. The optimal retail price is $[a+2(c+m)] / 4$, by first order condition ${ }^{4}$. Substitute $r=[a+2(c+m)] / 4$ into (3), (6), (7), (8) and obtains the price, quantities and the profit functions of upstream and downstream firms in Equations (9) and (10):

$$
p=\frac{5 a+6(c+m)}{12}, q_{1}=\frac{5 a-6(c+m)}{6 b}, q_{2}=\frac{a}{6 b} .
$$

From the (9), the profit function of the up- and the downstream firms, respectively,

$$
\begin{aligned}
& \pi_{1}^{u}=\frac{a^{2}+12(m-c)(a-c-m)}{24 b}, \\
& \pi_{1}^{d}=\frac{[5 a-6(c+m)]^{2}}{36 b}-f, \\
& \pi_{2}^{d}=\frac{a^{2}}{36 b} .
\end{aligned}
$$

Compare with (4) and (10), the difference of fim1's earnings will decline in upstream market as $m$ increases, but the second firm (i.e. the existing firm) profit is unchange with $m$ increases. Hence, Lemma 1 towed as follows:

Lemma 1 Suppose that $a>2(c+m)$. An increase in the markup levels do not change the output level of Firm 2. In addition, when the markup levels increases, the profit of Firm 2 be a constant in the final market, but the declines upstream firm profit in the capital market.

Calculate the welfare under the extended model as following:

$$
\begin{aligned}
\text { Welfare }_{e}= & \frac{[7 a-6(c+m)]^{2}}{288}+\frac{a^{2}+12(m-c)(a-c-m)}{24 b} \\
& +\left[\frac{[5 a-6(c+m)]^{2}}{36 b}-f\right]+\frac{a^{2}}{36 b}
\end{aligned}
$$

Using the (5) and (11), we investigate the effects of lowering the markup levels on the difference of the benchmark and the extended model. Differentiating the difference of the benchmark and the extended model with respect to $m$ by the chain rules and the following equation can be given:

$$
\frac{\partial \Gamma}{\partial m}=\frac{\partial \text { Welfare }_{e}}{\partial m}=\underbrace{\frac{\partial c s}{\partial m}}_{(-)}+\underbrace{\frac{\partial \pi_{1}^{u}}{\partial m}}_{(-)}+\underbrace{\frac{\partial \pi_{1}^{d}}{\partial m}}_{(-)}+\frac{\partial \pi_{2}^{d}}{\partial m}<0 .
$$

${ }^{4}$ By our above assumption, $a>2(m+c)$, we can obtain the equilibrium retail price be lager than zero.
There are four effects on the welfare level in the Equation (12): The first, second and third terms have negative effect on the welfare level when the markup level increases; the fourth one has no effect on the welfare level as the markup level increases. These results can summarize as the following proposition:

Proposition 2 An increase the markup levels to the welfare effect of the duopoly in downstream market is negative under the condition $a>2(c+m)$.

Equation (11) indicates that the changes of markup level will affect consumer's surplus and the expanding upstream firm. The commodity price will rise and quantities decrease when parameter $m$ increases and then reduce the consumer's surplus, therefore the rise of markup increases the degree of exploitation. In the upstream market, the increase of $m$ will reduce $q_{1}$ and made $\pi_{1}^{u}$ shrink when $q_{2}$ is given. In the downstream market, the increase of $m$ has two effects. First, $m$ raises the marginal cost and causes the equilibrium quantity $q_{1}$ declines (direct effect), the other is $m$ drives the retail price go up and lower $q_{2}$, brings the strategic substitution with his production part in downstream (indirect effect). The markup level has negative effect in $\pi_{1}^{d}$ if we sum these two effects. Finally, the change of markup has no obvious effect in original downstream firm. The rises of $m$ enhances the marginal cost in firm 1 and make $q_{2}$ increase by strategic substitution, but also heighten the retail price $r$ and brings a negative effect in $q_{2}$.

\section{Conclusion}

To investigate the changes of welfare and the degree of exploitation in consumer side when the upstream firm enters the downstream market, we construct a quantity competition model to analyze the changes in consumers' welfare and the profits of upstream and downstream firms. In conclusion, we find that markup has a negative effect in consumer's surplus and the degree of exploitation will deteriorate when the upstream firm enters the other market. Also we find that the profits in the firm which expands his production scale to downstream will decline when the markup level rises, but with no obvious effect in original downstream firm. These results are mainly due to the strategic substitution. The competition and the substitution of commodity increase in the downstream market when the upstream firm enters. Therefore the change of markup influences the commodity quantities and brings firms' strategic substitution, then alters their profits finally.

\section{REFERENCES}

[1] M. L. Katz, "The Welfare Effects of Third-Degree Price Discrimination in Intermediate Good Markets," American Economic Review, Vol. 77, No, 1, 1987, pp. 154-167. 
[2] P. DeGraba, "Input Market Price Discrimination and the Choice of Technology," American Economic Review, Vol. 80, No, 5, 1990, pp. 1246-1253.

[3] N. Economides, “The Incentive for Non-Price Discrimination by an Input Monopolist," International Journal of Industrial Organization, Vol. 16, No. 3, 1998, pp.271284. http://dx.doi.org/10.1016/S0167-7187(98)00005-8

[4] D. S. Sibley and D. L. Weisman, "Rising Rivals' Costs:
The Entry of an Upstream Monopolist into Downstream Markets," Information Economics and Policy, Vol. 10, No. 4, 1998, pp. 451-470.

http://dx.doi.org/10.1016/S0167-6245(98)00012-2

[5] G. Chemla, "Downstream Competition, Foreclosure and Vertical Integration," Journal of Economics and Management Strategy, Vol. 12, No. 2, 2003, pp. 261-289. http://dx.doi.org/10.1162/105864003766754224 